\title{
What has happened to firstborn social theory: the social contract
}

\section{Introduction}

According to those social theories which can be subsumed under the common title of atomism, the original human condition is solitary. It is only from such a solitary stance that individuals can enter a social contract, which most theories describe as an essentially interest-based arrangement where one trades-off one's intrinsic, and in principle unlimited, freedom in exchange for a degree of fundamentally biological protection that is possible only in a collective of individuals. The attraction of social contract throughout the modern history of philosophy has arisen from its easy compatibility with liberal sentiments. The predominance of liberal thinking in political philosophy has ensured that the 'generic' explanation of society along the lines of a social contract would be broadly accepted and elaborated. Assuming that the protection of individual liberties and the curtailment of the state to the minimum necessary to benefit the most, while allowing the maximum possible liberty to each one member of a society, is the value to guide political philosophy, it has been highly convenient for philosophers to trace back the very legitimacy of society to a pre-social situation where individuals had supposedly enjoyed unlimited freedom and would have decided at one point to join society.

In the described context, it is not actually important that social contract theory does not postulate a factual solitary state at any particular point in human history but simply assumes one for reasons of theory. The very assumption warrants that, if the theory is valid, such a factual situation must at least have been possible. In other words, social contract goes hand-in-hand at least with traditional liberalism. I shall try in this article to discuss the compatibility of liberalism with organic solidarity which, I shall argue, is a prerequisite for any effective form of social integration within existing democracies. Such solidarity is required, for example, for union activities and the ability of members of groups to identify with each other on a basis broader than crude and obvious interest. My point will be that organic solidarity requires a sufficiently broad range of shared values that they could constitute a particular passion of commonality. Finally, I shall argue that, without such a passion of commonality, there can be no adequate social solidarity that would be truly useful in highly complex modern democratic societies and that the liberal tradition today militates against such instrumentally necessary solidarity.

I shall discuss these issues in a free form and will not adhere to technically strict standards in order to allow for a broad range of issues to be encompassed in a relatively short discussion. In addition, it is not the aim of this article to be argumentatively tight in the usual analytic way, but rather to relate issues preliminarily that may later be elaborated through a more stringent methodology.

\section{The atomistic individual}

The reality in most societies that exhibit the anatomy of modern democracy in its formative sense, namely in so-called transitional societies, reflects only too well the 
assumed pre-social, atomistic nature of individuals. A lack of institutional protection, due either to dysfunctional institutions or to corrupt ones, extreme social vulnerability and a lack of a coherent system of values to cling to arguably represent some of the major issues for modern democratic theory as well as policy. Integration through professional groups, non-governmental organisations, unions or guilds is proving difficult, and the definition of the policy of such groups even more so, because of the fractured values and diminished capacities for joint action. It is easy, and sometimes politically profitable, to blame such a state of affairs on any current constellation of political parties or broader circumstances, but a look behind the façade, in the theoretical bosom of the problem, shows that the way people think forms their democracies, their groups and unions, and that the ultimate responsibility for obstacles to joint action lies in philosophy; more precisely, in the philosophical roots of the way in which one conceives one's social surroundings. Such roots are more common to us than we are inclined to admit and they almost always arise from the sentiments of liberalism.

The inheritance of social contract thinking is intimately present in the daily perceptions of social interactions. Søren Kierkegaard wrote in his Either/Or: A Fragment of Life that old age tends to turn the dreams of youth into reality, in a way well illustrated by someone "who in his youth had built a mental hospitality, only to be admitted to it in his old age'. In a similar way, the social contract hypothesis of the atomistic state of individuals has turned into the ugly reality of a factual atomistic state of bewildered individuals seeking collectivity in mature liberal democracies. The absence of organic solidarity in the initial concept of the social contract has naturally bred liberal political systems where the absence of such solidarity is painfully obvious to anyone involved in trying to mobilise collective social action.

The concept of mechanical solidarity, inherent in the social contract, indeed allows for a seemingly successful account of the legitimacy of society based on individual liberty and free will. However, a society so built is prone to an equally successful process of mental disintegration manifest in the propensity of individuals to distance themselves from collective values. If I am free to join a collective when it is in my immediate interest, and to the extent to which it is in my interest, then I do not have a lasting commitment arising from the very definition of what I am which would relate me to the society and I am free constantly to re-examine my own belonging to the group in light of my current interests. A liberal citizen is in a constant process of the re-examination of one's fact of belonging, and of one's extent of belonging, to any particular group including the society. One cannot exit the society in the institutional sense of returning into a fully pre-social state, but one can and often does remain dissociated from it in ways just short of falling out. Democracies without solidarity amount to little more than empty institutional shells that can easily turn into disguised dictatorships and this is why democratic theory is so full of appeals to what Jürgen Habermas has termed 'participative democracy'; in other words, to fostering organic solidarity and active participation in political processes conceived as essentially social processes.

Both modern liberals and their opponents, communitarian theorists, have tried to address the problems arising from the absence of organic solidarity in methodologically very different ways. 


\section{The liberal cure: collective rights}

One way to address a lack of organic solidarity is to take a decidedly liberal stance and try to found solidarity in collectives smaller than society, yet found within existing democratic societies. The champion of this approach in modern liberalism is probably Will Kymlicka. The argument goes roughly as follows. Dissociations in modern democratic societies take many forms, but one of the most noticeable is that arising from increasingly diverging group interests and projections of the collective futures of particular collectives within the society. Such situations are particularly easy to discern where national groups inhabiting an easily delineated territory and with an articulated leadership are concerned. Debates over collective rights in such cases seem to reflect the crisis of community, yet they arise from a lack of respect for individuality that is constitutive of any meaningful collectivity.

The argument further points out that wherever the existing states, and with them their societies, are threatened by autonomy and secession movements, what is at stake is, in fact, the need to guarantee an adequate level of individual rights through granting a high degree of autonomy to groups because, and this is crucial, only such collective rights, when granted, will warrant the respect of individual rights. In other words, groups gathered around a grievance or a collective political projection, such as an autonomy in, or an independence from, an existing state, express the frustrated projections of individual members over the control their own future. The only legitimate way to address such individual projections fully is to provide the sought-after political collective rights because they are the only environment in which individual freedom can flourish at this next stage of its cultivation.

Thus, modern liberals advance 'a decidedly liberal' argument for political autonomies and the collective political rights of ethnic groups and other collectives that broadly satisfy what are essentially criteria of easy discernibility in modern societies: such rights should be granted because they are a sign of a progressing regard for individual rights. Liberal societies, thus, must be highly prepared to grant political autonomies and even re-draw their borders whenever sufficiently coherent societal groups raise their voice with such demands. ${ }^{1}$

Much is true in the argument that individual autonomy sometimes requires collective rights and is best approached through the granting of such rights, but this does little for the problem of solidarity because autonomy is a formal pre-requisite for the moral evaluation of individual actions. In reality, however far the existing pre-conditions for such autonomy are pushed, the atomistic situation is not averted because it is possible to be highly autonomous, with or without collective rights, and yet profoundly a-social and devoid of capacity for solidarity. In fact, moral authority can be effectively fostered through decisive dissociation from collective efforts. Solidarity as the fundamental problem in democratic societies does not profit from the formal facets of individual autonomy, and collective rights, while they may or may not enhance autonomy, do not in any significant way enhance the capacity of individuals for collective action and for sharing collective values. Given that values fundamentally guide any human action, fostering the value of autonomy may, and usually does, re-

1 One of the most recent and comprehensive accounts of this liberal argument can be found in Steven Wall (2007) ‘Collective Rights and Individual Autonomy' Ethics 117(2), January: pp. 234-64. 
sult in quite the opposite of solidarity: namely, atomism as a social problem for democracies. ${ }^{2}$ In addition, groups rallying behind a claim of collective rights do not necessarily have a high degree of organic solidarity from the inside; they all too often disintegrate immediately after the initial goal is achieved, which can be seen in many, though not all, states established through self-emancipation movements. It appears that the implicit social contract transforms throughout the dynamic history of a group: once collective energy is mobilised for the goal of achieving ethnic autonomy or independence, for example, the bundle of solidarity becomes tied to that particular goal and tends to dissipate once the goal is achieved. Political alliances and projects built around single issues rarely last beyond the resolution of such issues, which means that they do not represent organic, but mechanical, solidarity. The thinking based on autonomy for individuals through rights is a par excellence social contract thinking that does not transcend the boundaries of what seems to be the contract's inherent atomism.

\section{The communitarian response: collective capacities}

Another way of addressing the solidarity problem is the communitarian argument that both justice and solidarity need to be viewed in terms of certain individual, but also collective, capacities and that, without collective capacities which ground solidarity, some types of social justice are not possible. Charles Taylor and Amartya Sen are perhaps the most widely discussed proponents of this type of argument. According to the argument, the more solidarity-friendly concept of autonomy and freedom than the liberal one is that based on ability to participate in collective action. Given that, according to communitarians, only these capacities allow individual development, since mankind is essentially social, freedom is exhibited more in the ability to develop through active social participation than in the ability to re-affirm one's atomistic individuality either with or without collective rights. This is a fundamental departure from the liberal tradition, because the thesis that development through collective action is an essential ingredient of freedom requires intersubjectivity for freedom without which there can be no collective action. Intersubjectivity, on the other hand, requires at least a minimum of joint values in order to motivate any meaningful joint action. Furthermore, the solidarity required by the communitarian argument is organic because it is grounded not in interest but in an intrinsic social orientation of freedom through development in a group.

This very simple angle on development makes all the difference between solidarity as a mere mechanical precept of the social contract (in which context atomism appears to be the inevitable outcome of old age making a reality of the dreams of youth) and solidarity as a moral category. If one's freedom is based on one's ability to develop through intersubjective relations and collective action, then one's capacity for collective action is built into one's core moral values and the key features of society are to be viewed through those mechanisms and dynamisms within it that enhance or debilitate collective capacities. ${ }^{3}$ Such collective capacities, importantly, must not be

2 Susan Gardner puts it: 'The most fundamental axiom that needs to be grasped in order to understand human action is that value creates all animate behaviour'. See Susan T. Gardner (2001) 'Autonomy: A Philosophical Capture' Practical Philosophy 4(2): 19. www.practical-philosophy.org.uk [accessed 22 November 2007]. 
reducible to a mere aggregation of individual capacities and must operate as a precondition for the possibility of the constitution of identity, in particular for the formation of so-called deliberative preferences and namely for the crystallisation of values that guide actions and decision-making in important life situations. ${ }^{4}$

The choices one makes constitute one as a social being while, in the communitarian framework, the values that ground such choices must fundamentally relate to collective projects. When social justice is at stake, the communitarian view naturally presumes that the achievement of common goals is the standard for justice and that individual merit is to be measured by the degree to which the individual has contributed to joint action. Liberals, on the other hand, focus on distributive justice, in the sense of the limits and direction of the legitimacy of the state in forcing redistributions of wealth and the structures of its regular distribution given the nature of democratic society. The nature of the prevailing concept of justice, and in fact of society as a whole, will thus largely determine the way in which social initiatives will be conceived and viewed by the public. This concerns union activism as well as academic, guild or ethnic initiatives.

\section{Social activism}

The theoretical conception of social contract has its equivalent in the idea of a social agreement between employers and employees, where both have opportunities to aggregate interests through joint actions in employer associations and unions of employees. Action in unions has traditionally depended on a larger degree of solidarity than that warranted solely by mutual interest. Like any other structured social action, union activism depends for its durability and lasting impact not just on aggregate interests but on a particular spirit of solidarity within the union which will see the joint action through, even in socially or economically adverse circumstances. The atomistic origin of the social contract appears to be lost in social activism because such atomism would naturally facilitate a speedy disintegration of the social contract into the original atomistic situation wherever the aggregate interest dissipates into atomistic interest as the presumed original condition.

This may seem too abstract but, more concretely, it means that pure interestdriven rationalism is insufficient to motivate and sustain any complex joint action, just the same as it is insufficient to ground any lasting commonality of endeavour such as a functioning democratic, participatory society. What is lacking is the emotional element that Robert Solomon so poignantly defended under the name of passion. ${ }^{5}$ Solomon writes against the idea of social contract:

[...] it makes no sense to talk about human nature - whether as pure rationality or productivity and possessiveness - apart from those features that we cultivate and acquire in society, and at the same time $[\ldots]$ there is no need to bring in rationality as a corrective for an essentially

3 A good recent account of collective capacities is by Gustavo Pereira (2006) 'Capacidades individuales y capacidades colectivas' Systema 195, Novembre: 35-51.

4 ibid.p. 44.

5 Solomon has written extensively on the subject, but for a practical illustration see Robert Solomon (1990) A Passion for Justice: Emotions and the Origin of the Social Contract Addison-Wesley Publishing: Reading, Massachusetts. 
selfish human nature. Our affiliations in society and with each other are not rational or a matter of self-interested calculation but a product of natural feelings and affections. It is selfishness and not society that is unnatural and justice should not be conceived as a rational corrective to our natural human emotions. ${ }^{6}$

To achieve a collective goal, more than one individual must be driven by a passion of commonality that transcends in its reach the immediate aims and interests of any one of them and that sets its sights on a future community such as they want to make it. Social activism is thus a passion for social development and any attempt to reduce it to sheer rationally conceived interest deprives it of any chance to succeed.

The 'natural feelings and affections' at work here arise from cross-self identification within a group and, clearly, the main mechanism facilitating such cross-self identification is empathy which Max Scheller considers so crucial to human relations that he posits it at the base of all morality. Once members of a group are able sufficiently to empathise with the other members of the same group, that group becomes sufficiently coherent for lasting collective action and assumes a stable collective identity.

Social activism is thus grounded in emotions, passions and natural affections, rather than in abstract presupposed rational contracts, and, in fact, functioning societies are ones where the high degree of mutual solidarity between their members arises from greater mutual affections. This is the true meaning of patriotism and the slogans calling for the love of one's countrymen and women or the members of other groups with shared values. In fact, it appears that liberal thought, so fundamentally based on the idea of a social contract, if only as a theoretical presupposition, has not only systematically atomised the democratic citizen but has also deprived one of the ability to extend affection to other members of the group, thus crippling the ability of social groups to foster an effective participatory dynamic within democratic institutions.

The obsession with 'rights' and 'entitlements', mostly conceived in negative terms, such as 'freedom from' interference, imposition or dictatorship, or 'entitlements to' individual autonomy and the like, has neglected more promising values such as the virtue arising from commonality and the ability to foster various commonalities, giving rise to different forms of collective action. The modern liberal individual is perhaps reasonably well protected from interference, at least in the bestdeveloped, functioning democracies, but even in such societies that are economically well-off and where individuals are relatively autonomous as moral agents, a frightening gap yawns between the autonomous individual and any meaningful extension of one's identity into the common sphere. The reason for this lies simply in that, in order to develop a common identity, an autonomous individual decision is far from sufficient; what is needed is an actual skill and ability to do so. That skill requires the emotional prerequisites that have much to do with the long-forgotten passions and affections so carefully subdued in the course of the cultivation of a rational liberal society.

What I call the passion of commonality is thus in fact a prerequisite for meaningful social action and, in particular, for any type of social activism. Most religions have depicted this more or less general affection between the members of a society as a pervasive 'love of each other' and, in fact, such a view deeply contradicts the age

6 ibid. p. 62. 
long, yet profoundly odd, stereotype of a selfish individual forced to make compromises for the sake of survival and thus generating social bonds as offshoots of the same selfish struggle to make it through the life course. Religions have postulated affection, or 'love', as indeed the anthropological building block of society but also of individuals. Solitary confinement is considered a harsher punishment than an equal time spent in a shared cell. This is not just because one is bored, but because one's human faculties are immobilised and one such fundamental faculty is what John Searle famously labelled 'intentionality', or a fundamental directedness towards each other, a fundamental disposition for inter-subjectivity, communication and sharing. Loyalty in its true sense is possible only where there are shared emotions and a sense of altruism, even if it is mediated or even conditioned by a system of mutual rewards and respect, and even if it cannot survive without being returned. In this sense, it is perhaps less idealistically conceived, or it has perhaps lost some of its original appeal, but it remains the glue of any coherent group, especially an organic society of individuals with shared values and strong mutual bonds. A society without mutual affectionate bonds does not really allow genuine solidarity but merely mutual projects that arise from calculated interest. I suspect this is the reason why so many social projects tend to collapse after a grand start. The start is due to highly sophisticated calculations and predictions of success but the failure arises from the lack of true recognition of each other.

\section{The operational framework}

Social contract theory has provided a seemingly appealing operational framework through a supposed contract into which individuals enter, thus committing themselves to society. The commonalities-based approach is better accommodated in what is known as the game framework. This assumes that social interactions can be described as a series of games with specified rules but which cannot be played without the voluntary participation of all those who hold a stake. In a game, rules determine permitted and non-permitted moves but the motivations for the actual taking of particular moves arise equally from rational calculations, primarily of consequences, and from passions.

Solomon rightly points out that most games are such that, in fact, all players benefit from them because of the intrinsic pleasure of the game and that most games are free of the pressures inherent in often-discussed 'zero-sum games'. The game of social life is equally a matter of passions as well as calculations, while the way one moves through the game depends on the delicate balance between one's passionate faculties and one's rational faculties, including to which of these one gives precedence. One's life path is more irrational and oriented towards the satisfaction of desire; another's is almost completely rational and planned - yet, even in the most rational life paths, one often finds an emptiness that results from a disregard for passions.

Solomon's description of how games work is helpful here:

One problem with the game analogy is the fact that we so often tend to think of games in terms of one particular type, the so-called zero-sum game. A zero-sum game is distinguished by its utter competitiveness. One person (or team) wins, the other loses. Or, if there are several players, the sum total of all winnings and losings is zero. (...) Even here, of course, the 
over-riding interests of group integrity are obvious even if not center stage: people play poker for shared enjoyment or mutual distraction; it is only the occasional 'big game' or a player's getting in over his head that allows the zero-sum character of the game to eclipse the shared objective. Team sports presuppose tremendous amounts of group cooperation and coordination as well as competition. In fact almost all games pay off for all participants quite apart from the inner logic of winning and losing. In practice, the zero-sum game is something of a myth, and it is only in theory that most of our favorite games are zero-sum games. ${ }^{7}$

On the one hand, social activism, especially union activism, often appeals to zerosum game-related concepts, such as survival of workers, basic social values and the structure of wealth in society, with all of its existential consequences. Even so, this is a game of power within society that many play for the pleasure of it, while the benefits for workers that arise from successful moves bring satisfaction of their own to the key players. Playing for social justice is more satisfying on many counts than playing in a team within a structurally violent society prone to exclusion and exploitation - although both teams play within the broad frameworks of the loyalties and basic values that keep them together. Further still, both sets of values are sub-sets of a larger set of values that keeps together society and the industrial system as a whole. Unions will play employers on an even or slightly sloping field, but both groups will stop short of engaging in violence or such a level of industrial unrest that might disturb the structure of the economy, unless certain real dimensions of a zero-sum game emerge. Revolutions have occurred exactly at those periods where the game was forced, or neglectfully allowed, to become or to be perceived as a zero-sum game. As long as the game remains within tolerable bounds, given the existing social institutions, it allows for a full range of reflection of the various mutual affections within and between the groups who play.

Similar considerations apply to different and politically more ominous games, such as issues of the so-called national interest. Small nations often face challenges to their territorial and state sovereignty that put their mutual loyalties to the test. An effective performance in a struggle to protect such interests all too often reveals a profound lack of mutual loyalty and affection, and makes obvious internal power struggles based entirely on the atomistic, barren interest of the power elites. In such situations, communities are, in fact, seen as stripped of their attributes of commonality and, typically in such situations, they lose the games. The more loyalty a community shows towards the common cause, and the more mutual respect and commonality as a quality of mutual relations there are, the better the odds that the game will be won, even if the initial chances might be extremely meagre.

Political struggles around the world show this: the Israeli struggle against the Palestinians and vice versa is an example of high cohesion within the Israeli camp and relative divisions within the Palestinian team, resulting in a disproportionate effect for the game given the human and geographical resources at stake. The Serbian struggle over Kosovo shows a similar pattern, with a high degree of mutual support within the Albanian camp and divisions and mutual backstabbing in the Serbian political camp, which can only result in the Serbian side losing the game. The internal ' $x$-ray' of the

7 ibid. p. 131. 
passions and interests at stake within each camp will relatively successfully reveal the most probable outcome of the game.

This goes for any activism, whether it is motivated by national, industrial or any other commonalities. Such commonalities have a strong chance of winning only if they are permeated with emotional bonds and shared values that are sufficiently strong to put any individual differences or brinkmanships on the backburner.

In short, what we have at stake here is a dialectic between the principle of commonality and the liberal principle of individual projections of interest. Collectives construed mentally from the bricks of liberal individualism and their intellectualist projections of collective rights and interests have always been far weaker in the game of social and political interactions than collectives based on the passion of mutuality and a strongly-shared affectionate identity. The latter, unlike the former, have proven able to sustain the long haul of struggle and to support their members in times of crisis and distress; the former, on the other hand, have created internal conditions of the 'survival of the fittest', thus generating an atmosphere of hidden fear and mutual distrust, and have consequently failed in sustaining joint projects for their nation, for their interest-group or for their local community.

One question not yet addressed is how mutual affections might develop in a community. Clearly, there are many communities without such internal bonds and many function almost as virtual communities, in fact as aggregate groups of individuals with shifting coalitions of interest and otherwise left to their own devices to make it through the life course. An explanation advanced by Solomon, but equally by Robert Singer and others, is that we have a natural propensity for altruism, primarily directed towards those closest to us, our next of kin. Protecting one's offspring is characteristic of all animals and aiding one's children through at least a part of their life course is a common thread in all human cultures.

This narrow circle of subjects to whom altruism flows naturally can be expanded through a growing familiarity and ability to identify with a larger family, for example, and this circle can be further expanded to include neighbours and colleagues from work, all the way to one's 'nation' and, according to some philosophers, even more radically, to 'all of the human race'. In fact, it seems to me that this is how nationalism primarily functions; if it is a positive and healthy phenomenon, it is based on a successful series of enlargements of the initial circle of altruism to include all those with whom we can identify as members of the same community or nation. Perversions of this process are, unfortunately, only too familiar, where manipulation by selfish elites has caused the enlargement of circles to deviate in ways contaminated by a hatred of others and by artificial divides marking 'others' who are not really so different but who merely hold different interests from the ruling cliques of one's own community. This, for the most part, was the story of the wars in the Balkans.

Enlarging circles of altruism account well for the possibility of social activism because they allow the creation of composite identities based on certain aspects of our life. If one is a worker in the electronics industry, one will share many experiences, issues and grievances with all the other workers in the same industry and, if the organisational and social conditions are there, one will be able to connect horizontally and become a link in the chain of union action that might prove highly effective. Such action will necessarily encounter difficulties and the diverging interests of the various 
parts of the chain and these will be the tests of loyalties and the degree of cultivation of altruism and mutual affection within the entire electronics union movement.

The same applies to political parties. Often they are subject to an authoritarian leadership that calls itself 'democratic', but many political parties were formed on the basis of ideals that have never fully lost their appeal. If there is a sufficient core of members who nurture and preserve the emotional potential arising from those ideals and common struggles, the party will be able to survive periods of perverse leadership, or perversions of its initial leadership, and turn these into productive ingredients for a dynamic and intellectually opulent political life of one's country. On the other hand, if most of the members have joined the party merely because of interest, or because they perceive the party in the politically correct way as being merely the legitimate vehicle for one's individual political promotion, then such parties will not have a bright future given the calamities of corruption of political life and especially of leadership.

There are two negative aspects of commonality based on altruism as well. Firstly, such commonality functionally depends on a game model in which reciprocity is normally expected and where any attempts to exploit the group's altruism by not fulfilling the legitimate expectations of others is punished either by marginalisation or exclusion. Cultures of commonality are, thus, not very 'soft' on transgressors, even though they are extremely supportive of those who value their own contribution to the group and who cultivate values based on the virtues of commonality. In liberal cultures, there are fewer and less dramatic sanctions for failing the expectations of others because relations are defined predominantly in terms of 'rights', where negative 'rights', such as freedom from coercion or interference, are much more numerous than positive 'rights', such as the right to be a part of common endeavours. Liberal cultures are, hence, better suited for apathetic individuals while the rights of such individuals might be under strain in a culture of emphasised commonalities.

Secondly, commonality, dependent as it is on enlarging circles of altruism, is also prone to sibling rivalry: not infrequently, cultures or groups based on family-type familiarity and mutuality develop strong animosities that arise from their closeness. The phenomenon of one brother hating another is well known in all tightly-knit communities, including social movements such as unions, where cut-throat battles have been known to erupt between union leaders or sister unions even in the same industry. In the context of nationalisms, small nations very close to each other, with similar historical experiences, a shared territory or adjoining territories, and a relatively small joint gene pool, have been known to engage in some of the bloodiest regional conflicts in modern times. A good example is the love-hate relationship between Serbs and Croats, who share so many cultural and other traits: a relationship that could be compared, if it was not so violent in some of its episodes, to a tumultuous brotherly relationship during a maturing process. Again, this situation describes well the wars of the former Yugoslavia but also many social movements where internal differences have been exploited by outside interests to defeat the movement.

The game framework is perhaps well exemplified in team sports, where successful performance is so dependent on an enormous amount of practice in co-ordination and a careful division of roles, and where both practice and the shared experience of competition foster and reinforce mutual affections within the team and build team loyalty. The more advanced the team, the more all its members would have invested in its 
construction, in terms of time and effort, which then implies that the team represents more of their integral identity as persons. Consequently, the better and more cohesively the team is glued together, the more difficult and unlikely it is that any individual members would opt to leave it and the more severe any sanctions through marginalisation or exclusion tend to be towards any member who transgresses the rules. If life is a game, then team sport exemplifies it fairly well.

\section{Conclusions in brief}

Social contract theory is perhaps the most traditional modern political theory but, even if so, it is deeply mistaken and, in fact, it is responsible for many of the failures of modern liberal societies. Liberal thinkers have sought to locate the roots of the problems of modern liberal democracies in the failing mechanisms of social institutions, but the real problem is more in the minds of liberal citizens and in the very philosophical conception of liberal society. Liberalism has sought to extend social contract theory so as to account for the social nature of individuals through a number of overarching interests that necessarily bind together otherwise inherently solitary individuals. This tension of liberalism has accounted for its tendency to exhaust itself in elaborating various negative rights that would protect essential solitude while, at the same time, attempting to shield the individual from the devastating consequences of solitude through the various versions of the social contract chimera. In this sense, contract metaphor has lent credence to subsequent liberal doctrine and has equally been used by that doctrine to remedy some of its most unpalatable implications.

Game framework, on the other hand, allows for a ready incorporation of both rational calculations and passions, emotions and the mutual affections that represent the binding tissue of any functional collective. It rests on a passion of commonalities but is not immune from the deviations arising primarily from infighting and sibling rivalry described in the last section. However, it is a more realistic and liveable paradigm, and it is only within such a composite framework of both emotional and rational motivations that the successes and failures of social movements may be accounted for. 